\title{
VICTORY CELEBRATIONS AS THEATER: A DRAMATURGICAL APPROACH TO CROWD BEHAVIOR*
}

\author{
David A. Snow \\ Louis A. Zurcher \\ The University of Texas, Austin \\ Robert Peters \\ The University of Michigan, Ann Arbor
}

\begin{abstract}
Drawing on data derived from a field study of victory celebrations, this paper suggests a dramaturgical approach to crowd behavior. Existing theories of crowd behavior are either contradicted by the field data or do not adequately account for the heterogeneity of activity observed, for the interaction between the various categories of participants, or for the shifts in the behavior of the participants and the resultant change in the character of the celebrations. Subsequent analysis indicates that the victory crowds are best understood from a dramaturgical standpoint. Several theoretical, conceptual, and research implications of a dramaturgical approach to crowd behavior are suggested and discussed. The paper concludes with an expanded conception of crowd behavior, one which emphasizes its spatial and temporal as well as interactional dimensions.
\end{abstract}

Even though conceptual discussions of crowd behavior typically include some reference to social interaction or personal interstimulation (Blumer, 1951; Brown, 1965:728; Brown and Goldin, 1973:178; Lang and Lang, 1968:556; Milgram and Toch, 1969:507; Perry and Pugh, 1978:3) not enough is known about the structure and processes of interaction within collective encounters. Over two decades ago Blumer (1957:135) observed that "the retarded state of our knowledge in this area seems to be caused in part by the paucity of study of natural instances of collective behavior." In their recent review of the field, Marx and Wood (1975:372) similarly noted that "systematic empirical research during instances of crowd behavior has been significantly lacking."'

Inasmuch as research is guided by theory, it is not surprising that crowdspecific interaction has received so little empirical attention. With the exception of the emergent norm approach (Turner, 1964a, 1964b; Turner and Killian, 1972), theories of crowd behavior tend to focus not on what goes on within collective episodes, but on the dispositions (Allport, 1924; Feuer, 1969; Johnson and Fein-

*Direct all communications to: Dr. David A. Snow, Department of Sociology, The University of Texas, Austin, Texas 78712.

The authors wish to thank the anonymous reviewers and Peter $M$. Hall of SYMBOLIC INTERACTION for their helpful comments. 
berg, 1977; Miller and Dollard, 1941) or cognitive states of the participants (Berk, 1974a, 1974b; Blumer, 1951; Freud, 1922; LeBon, 1903). ${ }^{2}$ While such foci inform us about crowd participants and their states-of-mind, the nature of crowd-specific interaction and its relation to the development of crowd behavior remain problematic.

The purpose of this paper is twofold: (1) to contribute empirical data on crowd behavior by describing and analyzing a series of college football victory celebrations; and (2) to apply a dramaturgical analysis to crowd behavior, focusing on interaction rather than on the cognitive or demographic characteristics of the participants. The intent is not to displace existing approaches to the study of the crowd. Rather, it is to complement them, particularly the emergent norm thesis and the gaming or rational calculus perspective. ${ }^{3}$

\section{DATA AND PROCEDURES}

On five consecutive Saturday evenings from October 8, 1977 to November 5, 1977, students from The University of Texas and other Austin residents converged on the main street bordering the University and transformed it into an arena for celebrating the victories of the University football team. Data about the celebrations were derived from three sources. Following a team approach to fieldwork, we first observed the celebration in situ. One of the authors, who lived within earshot of the celebrations, assumed the role of a participant observer for each of the episodes. Another author, although attending some of the celebrations, functioned mainly as a detached observer. The participant observer roamed through the different spatial sectors of the celebrations, occasionally hitching a ride on a parading vehicle, and talked with representatives of the different segments of the crowd. He was able to record hundreds of behaviors and gestures and to interview informally several of the participants. The detached observer, functioning primarily as a cross-examiner, critically appraised the fieldnotes and interviewed the participant observer. Each Monday following a celebration the participant observer and the detached observer would meet in a debriefing session and establish a research agenda in the event of another celebration.

As a check on our own observations and fieldnotes, 15 university students, each of whom had participated in the victory crowds, were interviewed in the weeks following the celebrations. We were less interested in the representativeness of the student respondents than we were in how well their recollections corresponded with our own observations.

The third data source consisted of press accounts in the campus and city newspapers. These accounts, including letters to the editors regarding the celebrations, were examined for information about community reaction and for evidence confirming or disconfirming our observations. Although the three data sources yielded no major inconsistencies, it might appear that the data base was thin. We would argue, however, that the data we collected are far better than none, especially in a substantive area rife with theoretical sepculation about phenomena that have too infrequently been directly studied. 


\section{THE VICTORY CELEBRATIONS}

On October 8, 1977, The University of Texas football team unexpectedly defeated its arch-rival, the University of Oklahoma, for the first time in seven years. Immediately following the game's conclusion $(4: 30 \mathrm{p} . \mathrm{m}$.), many students and other local fans began driving along "the Drag," the section of Guadalupe Street bounding the western edge of the University campus (see Figure 1). Even though the game had not been played at "home," by 8:00 p.m. approximately 3,000 people had gathered on the Drag. There was bumper-to-bumper traffic between Nineteenth and Twenty-Sixth Streets (which constitute the northern and southern boundaries of the University campus). The street resounded with the din of honking horns and shouts of "we're No. 1!" The celebration, which was likened to "a big New Year's party" by one participant, lasted until early Sunday morning.

Throughout the evening six types of participants and corresponding behaviors were clearly discernible (see Figure 1). The first type consisted of the vehicular paraders or occupants of the motor vehicles who, as the focus of attention, constituted the main performers. A few of the cars had roof-mounted loudspeakers blaring "we're No. 1." All of the vehicles were filled with celebrants who, hanging out the car windows or sitting on the car roofs, guzzled beer, yelled, flashed the "Hook-em-Horns" sign, ${ }^{4}$ and slapped hands with other paraders and spectators who lined the street.

The second group of participants consisted of relatively passive spectators who sat on the cement wall that separates the University campus from the public sidewalk. Periodically a few of these spectators would yell and flash the "Hookem" sign, but their main activity was viewing.

The third type were the more animated spectators. Congregated mainly on the west side of the Drag immediately north of Twenty-Second Street, these participants actively supported the vehicular paraders by shaking their hands and cheering them on. Immediately behind these spectators was the fourth set of participants. This group consisted of a small number of people who were dancing to the rock music blaring out of a record store.

The fifth type was represented by males who stood across from the Student Union just south of Twenty-Third Street. Whenever a car or pickup approached, they would slap the side and top of the vehicle and attempt to "grope" the female occupants.

The sixth group of participants was comprised of the police scattered along the Drag. Decidedly friendly, the police appeared to function more as supportive viewers than as control agents. Except for keeping the autos within their appropriate lanes and occasionally asking some of the more animated spectators to move back, the police maintained a low and cordial profile. This was reflected in part by the fact that none of the participants at this first celebration were arrested, even though many of them were in fact breaking the law.

The following Saturday (October 15), Texas' football team came from behind in the final quarter to defeat the University of Arkansas. Moments after the game, fans again converged on the Drag. They began celebrating in a manner similar to the previous week, but with three discernible differences. First, there was a 


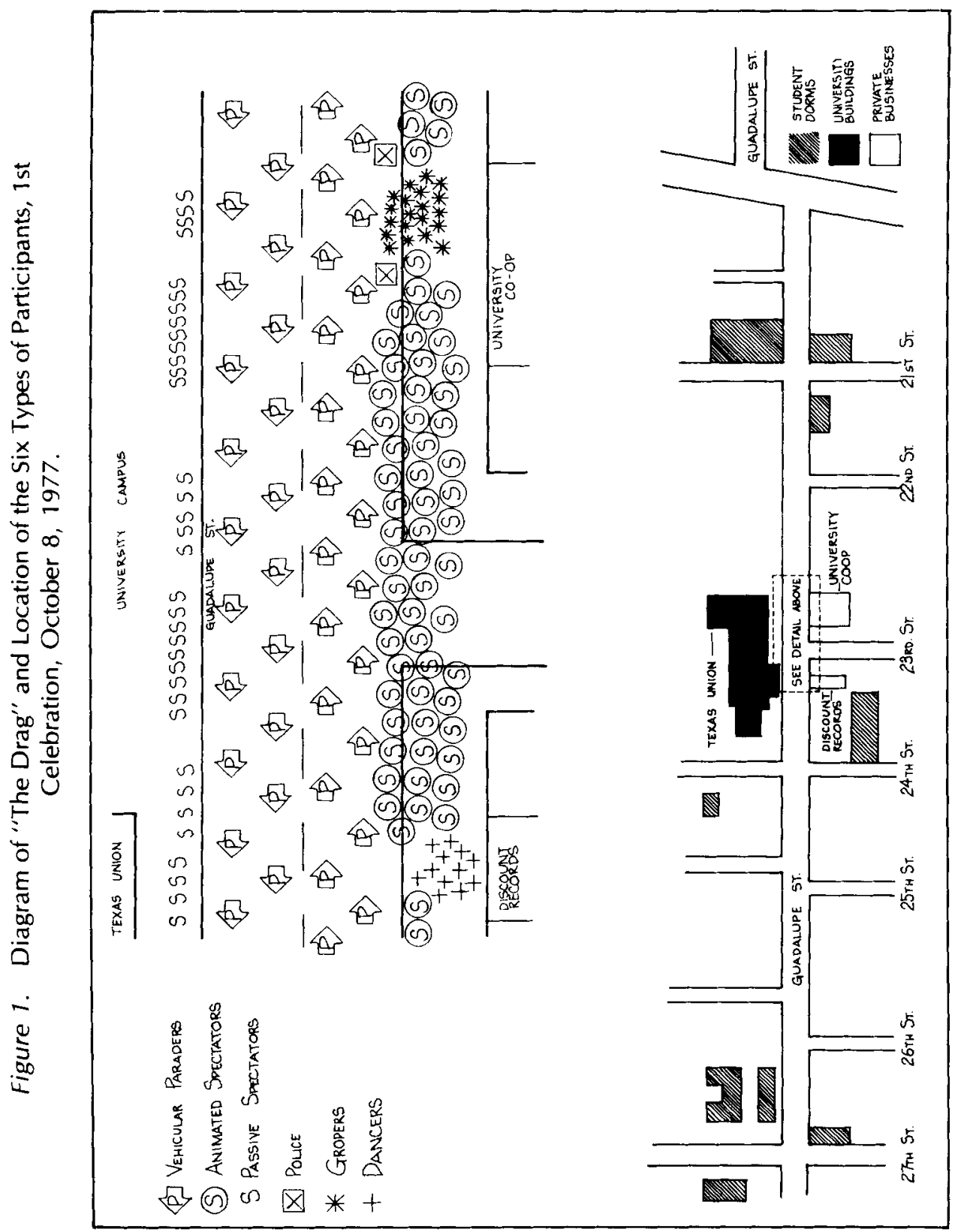


greater number of vehicular paraders. Not only was the traffic backed-up further than the previous week, but there were more celebrants sitting in and on the cars and pickups. Second, females were not being molested by male spectators. Third, not only had the number of spectators increased, but they had become more animated. As before, the police did little to dampen the jovial mood or to stop the celebration, which could still be heard from a mile away at 4:30 Sunday morning.

While Texas was defeating Southern Methodist University on Saturday, October 22, No. 1 ranked University of Michigan was losing to the University of Minnesota. This upset, coupled with Texas' win, meant that Texas would probably become the No. I ranked team in the nation. Partly because of this unanticipated turn of events, the ensuing celebration was the largest and most vociferous to date. Honking horns rhythmically pounded out "we're No. 1" while riders waved Texas state flags, shook hands with spectators and tossed cans of beer to those weaving in and out of the bumper-to-bumper traffic which extended 15 blocks in either direction. But most of this activity was not evident until the vehicular paraders entered the area of Guadalupe that had been transformed into an arena for celebration. As paraders entered the "stage," their level of animation increased and the noise became almost deafening. The crowd activity reached its peak in the vicinity of Twenty-Third Street and the student Union (see Figure 1), where the number of spectators was most dense. Again, the police were unobtrusive. Most of the time they stood watching the celebrants, occasionally shaking hands with some of them and flashing the "Hook-em" sign.

Following Texas' defeat of Texas Tech University on Saturday, October 29, fans again converged on the Drag. With bumper-to-bumper traffic extending for 34 blocks by early evening, it appeared as if the celebration would be the wildest to date. The fact that this was the first celebration to follow a home game also suggested a likely increase in intensity. However, the celebration was subdued and constrained in comparison to those previous. There was less physical contact between paraders and spectators. There were fewer celebrants per vehicle. There was less hand-slapping and little rhythmical horn-blowing. The overall volume of noise had decreased.

These changes in the behavior of the celebrants seemed largely due to a shift in police strategy and demeanor. The number of officers had increased from the previous week's level of approximately 5 per block to a new level of 8 to 10 per block. In addition, the majority of the policemen were now suited in high leather boots and riot helmets. Now, rather than shaking hands and flashing the "Hookem" sign, the police were concentrating on directing traffic, keeping celebrants off the tops and hoods of cars, and keeping spectators out of the street. In contrast to the earlier celebrations, the police were occasionally arresting lawbreaking celebrants.

Since these changes in police behavior interfered with the celebrating, some of the celebrants later in the evening $(11$ p.m.) shifted their activity further down the Drag where there were fewer police. Whereas the segment of the Drag directly across from the Student Union had functioned as "center stage," a substitute area was appropriated and redefined for celebration by some of the spectators. Until police reinforcements arrived at the new site, celebrants were once again sitting 
on car hoods and hanging out the windows, honking the car horns, walking back and forth between cars, shaking hands, and screaming "we're No. 1."

Texas' defeat of the University of Houston on Saturday, November 5, provided the impetus for another celebration. However, this post-game celebration was even more muted than the previous one. The major categories of actors returned, but their behavior had changed dramatically, as if the script had been rewritten. Though there were at least 1,000 celebrators on the Drag, there was little yelling. There were only scattered horn blowing and few overfilled cars and pickups. The mood was one of caution; the watchword was "Ssshhh." The apparent reason for the change was a significant increase in the number of police assigned to the Drag. Officers were standing every 30 to 40 feet on the center dividing line and on each side of the street. Police were stationed north of Twenty-Sixth Street for the first time since the celebrations had begun. The officers had been instructed (for reasons that will be discussed later) to reduce the overall level of noise. Whenever a horn was blown, the officer who spotted the violator would stop the vehicle or shine his flashlight on the side of the auto and the next policeman would stop the car. As a result of this tactic, the noise was greatly reduced.

Nonetheless, some vehicular paraders, coaxed by the spectators, continued to drive up and down the Drag. Whenever a car horn sounded, spectators in the immediate area would applaud and cheer. If a parader received a citation, the police were booed. Though the encouragement did not lead to an increase in the actual amount of horn blowing, it did help produce an atmosphere conducive to taunting the police. Many paraders would shout "honk, honk" as they passed police; others mockingly would put a finger to their lips in the "Ssshhh" position. In response, one officer commented, "I'd almost rather they did honk. At least there would be something to do." As the evening progressed, it became evident that the interaction between the police and the vehicular paraders had now become the focus of attention.

The following Saturday, November 12, when Texas defeated Texas Christian University, the only actors to appear on the Drag in full force were the police. There was little celebration; traffic was near normal. There were several reasons for the apparent disinterest in celebration. First, although Texas won, the victory was anticipated. Second, the Saturday morning edition of the city newspaper indicated that the police would attempt "to put a damper on any celebration." As on the previous Saturday, there were approximately 10 police per block. Moreover, they were giving a traffic citation to anyone who blew a car horn. This show of force and "crack-down" strategy seemed to intimidate potential celebrants. Only three "honks" were heard and recorded within a 15 minute period between 8 p.m. and 9 p.m. A third countervailing factor was the rumor that "a sniper would be on the Drag" on Saturday evening. Both Friday's edition of the campus newspaper and the Saturday morning edition of the city newspaper reported that the Austin police had received an anonymous letter warning that the writer would "shoot up the Drag Saturday night" in the event of another celebration. Although the police were "pretty satisfied it (was) just a crank," such a threat could not be fully discounted, especially since it stimulated memories of a sniper who in 1967 had terrorized the University of Texas campus. A fourth countervailing factor was 
the annual sausage festival (Wurstfest) south of Austin. The festival provided an entertainment alternative to the Drag, thereby siphoning many potential celebrants. Finally, it is reasonable to assume that for many of the participants the celebrations were becoming routine and predictable; the novelty had worn off.

After five weeks, the series of victory celebrations had run its course. In the weeks that followed, Texas won its final two regularly scheduled games. Neither were followed by a victory celebration of the kind that had occurred earlier.

\section{ANALYSIS AND DISCUSSION}

Students of collective behavior have long debated its proper conceptualization (Brissett, 1968; Couch, 1968, 1970; Currie and Skolnick, 1970; Marx, 1970; Smelser, 1970; Turner, 1964a, 1964b; Weller and Quarantelli, 1973). However, most scholars would agree that the victory celebrations on the Drag constituted a series of crowd episodes. On each occasion there was a large number of people in close physical contact within a limited spatial area. There was a common focus of attention. Though some "assembling instructions" (McPhail and Miller, 1973) such as shouts of "to the Drag" were heard after the first celebration, the assemblage and ensuing behaviors were relatively spontaneous and unplanned. The celebrations were neither on the community or university calendars nor were they the product of prior formal organization. This is not to suggest that the celebrations were devoid of organization or patterned behavior. To the contrary, it appeared as if the actions of the different segments of the crowd fit together, as if they were aligned in a complementary fashion. How can that coordination be best explained? How did the lines of action exhibited by the different categories of participants fit together and contribute to the development of the celebrations? Additionally, what accounts for the shift in the behavior of some of the participants and for the change in the character of the celebrations?

The dominant theories of collective behavior do not fully enough address these questions. In fact, they are contradicted by much of what we observed and heard.

\section{Convergence Theory}

Convergence theory views the action of crowd participants as parallel or homogeneous, and attributes this presumed uniformity of action to hypothetically shared backgrounds or dispositions among the participants (Allport, 1924; Feuer, 1969; Gurr, 1970; Klapp, 1969; Miller and Dollard, 1941; Toch, 1965). The key to understanding crowd behavior is seen as residing within the characteristics of the participants rather than within what transpires once they become part of the collectivity. This view was of little use for understanding the victory celebrations. The crowds were characterized by differential participation, and the crowd members were not of one mind or background. The majority of participants appeared to be U. T. students, but "students" hardly constitute a homogeneous lot in background, orientation and allegiance to the university football team. This is especially true at a large state university. ${ }^{5}$ Moreover, we observed considerable variation in the age, sex, ethnicity and style of dress of the participants. The convergence assumption that crowd participants are similarly motivated is also 
inconsistent with our data. Some participants indicated they were in the crowd because of "curiosity," some because they were diehard Longhorn fans, some because they thought it would be "fun," some because they had "nothing better to do," some because they were coaxed by friends, and some, such as the police, because it was their duty.

\section{Contagion Theory}

Contagion theory seems equally unhelpful when applied to the celebrations. It also views the crowd as a monolithic entity characterized by uniformity of behavior. Rather than explaining the presumed homogeneity of action in terms of shared characteristics that precede the formation of the crowd, contagion theorists (Blumer, 1951; Freud, 1922; LeBon, 1903) attribute it to a breakdown of participants' cognitive abilities. The reduction in rational faculty, coupled with the anonymity supposedly provided by the crowd, renders the participant susceptible to the uncritical acceptance and mechanical production of whatever suggestion is encountered. Hence, everyone behaves alike.

Our observations do not support that view. As already emphasized, the victory crowds did not involve uniformity of action. Instead, the celebrations were the work of several categories of participants engaging in rather disparate behaviors. Additionally, most of the participants could not be classified as social isolates or anonymous individuals lost in the crowd. Friends and acquaintances rode together in parading vehicles. Many of the spectators were in the company of familiar others. The police officers were at least acquainted with each other ${ }^{6}$

The hypothetical link between crowd behavior and crippled cognition (LeBon, 1903) or non-interpretive interaction (Blumer, 1951) is also at odds with much of what transpired. When the police first began to make a concerted effort to halt the horn-blowing, for example, most people who blew their car horns almost simultaneously waved to the spectators. Since this action increased the possibility of being stopped by the police, it might appear to have been mindless or nonreflective behavior. But the police at that time were only warning violators rather than giving them citations. Hence, the violators had little, if anything, to lose. Moreover, the risk of being admonished by a police officer is likely to have been offset by the receipt of recognition from the cheering spectators. What may have seemed to have been indicative of "irrational" behavior appears to have been the obverse. That is, the behavior of some of the participants appears to have been based at least in part on consideration of potential rewards and costs. This interpretation is also suggested by the response of the vehicular paraders when the police increased their ranks and became more intent on reducing the overall level of noise. Rather than continuing to celebrate as before, the vehicular paraders as well as many of the spectators became more cautious, modifying their activities so as to decrease the prospect of being arrested. They still celebrated, but in a more subdued way.

\section{Rational Calculus or Gaming Theory}

Since the adjustment of one's actions in response to changes in the behavior of another is indicative of interpretive interaction rather than circular reaction, our observations are consistent with the rational calculus or gaming approach to 
crowd behavior (Berk, 1974a, 1974b; Brown, 1965). This perspective argues that crowd participants "exercise a substantial degree of rational decision-making and" are therefore no "less rational than in other contexts" (Berk, 1974a:356). Crowd behavior is thus thought to be contingent on "enough crowd members" reaching "parallel assessments which make action for all a good bet" (Berk, 1974a:368). In other words, collective action in a particular direction is attributed to an aggregation of individual decisions defining actions as more rewarding or less costly than inaction. By emphasizing the rational element in crowd behavior, we think that the gaming perspective provides a necessary and empirically sound corrective to the one-sided image of crowd participants suggested by the convergence and contagion approaches. But the individual remains the primary unit of analysis and cognitive processes, albeit rational in character, the focus of attention. Consequently, the gaming model is not directly helpful to understanding how the actions of different segments of the crowd fit together and contribute to its flow and direction.

\section{Risky-Shift Theory}

The risky-shift variant of the rational calculus approach suggests that the direction of collective action is determined by a natural selection process (Johnson, 1974; Johnson, et al., 1977; Johnson and Feinberg, 1977). It hypothesizes that the course of action taken-from a number of possibilities suggested by leaders or keynoters-is the one which is congruent with the dominant mood or opinion within the crowd. A shift in the direction of high risk, for instance, is regarded as most likely when the dispositions of crowd members are skewed in the direction of risk-taking. Those people who are not disposed to shift are likely to withdraw from the crowd, thereby moving the crowd towards greater consensus and uniformity of action. Accordingly, whether a particular keynoter's or leader's exhortations function to move the crowd in one direction or another is dependent on the distribution of dispositions throughout the crowd.

This line of explanation may be especially pertinent in those situations where there are identifiable leaders calling for different lines of action. However, it is often unclear in many crowd situations whether there are in fact any leaders. Throughout the victory celebrations there were innovators who might be construed as keynoters, but certainly not as leaders in the traditional sense. Moreover, the innovators tended to be groups of people acting in concert rather than single individuals. The argument that the direction of collective action is primarily a function of the congruence between leaders' exhortations and dispositions within the crowd thus seems to pertain to crowds with clearly defined leaders and followers rather than to crowds comprised of several categories of actors. ${ }^{7}$ As a consequence, interaction between various segments of the crowd is ignored by risky-shift theory. ${ }^{8}$

\section{Emergent Norm Theory}

The approach that appears best to explain the victory celebrations is the emergent norm thesis developed by Turner and Killian (1957, 1972; Turner, 1964a, 1964b). Crowd behavior is taken to be regulated by a definition of the situation. The definition emerges from a process of crowd-specific interaction and hypo- 
thetically functions in a normative manner by encouraging behavior in accordance with the definition. While one could reasonably argue that the actions of the various groups of victory celebrants were normatively regulated, it is questionable whether there was a single dominant norm which all the participants supported. To the contrary, it appeared that whatever the emergent normative constraints, they were specific to the various categories of actors rather than to the collectivity as a whole. Additionally, the alteration in the patterns of activity we observed do not seem to be fully explained by the emergent norm thesis. Each week there were changes in behavioral patterns, with some being modified, some being added, and some deleted. During the initial celebration, for example, there was no distinctive pattern of horn-blowing. In the following week the honking of horns to the rhythm of "we're No. I" emerged as a dominant pattern, and then faded during the final celebrations. It might be argued that the shifts were due to the emergence of new norms; but such an answer strikes us as tautological. Moreover, it leaves unanswered the question of what accounts for the emergence of one particular pattern of behavior rather than another, and the question of how norms specific to different components of the crowd fit together in an interactive pattern.

\section{Summary of the Dominant Theories}

The existing approaches to crowd behavior do not adequately account for the victory celebrations that developed on the Drag. Those approaches either ignore or gloss over the existence of various categories of actors, the ongoing interaction between them, and the role the interaction plays in determining the direction and character of crowd behavior. There are three reasons for the oversights. First, the approaches fall prey to the perceptual trap of taking the behavior of the most conspicuous element of the crowd as typifying the whole crowd, thereby giving rise to the "illusion of unanimity" (Turner and Killian, 1972:22). Attention is directed away from the less dramatic segment of the crowd and their contributions to the collective episode. As a consequence, the range of interactions that occur within collective encounters are ignored. Turner and Killian (1972), who originally criticized the convergence and contagion approaches on these grounds, fall prey to this perceptual trap by emphasizing the emergence of a dominant norm that applies to all participants. Second, for all but emergent norm theory, individual participants and their states-of-mind (i.e., frustration, hostility, rationality) are the focus of research and analysis. Attention is thereby deflected away from crowdspecific interaction. Third, the bulk of the data on which much theoretical speculation is based has been derived from either laboratory experiments or post-facto interviews with participants. The importance of interaction between various segments of participants in relation to the development and direction of crowd behavior has been given insufficient attention.

\section{A Dramaturgical Approach}

Dramaturgy, as a mode of analysis, articulates the patterns of behavior occurring whenever two or more persons come into each other's presence. ${ }^{9}$ Attention is 
focused on social interaction rather than on the individual and his or her background characteristics and cognitive states. Drawing on the imagery of the theater, interactants are viewed as conducting themselves as if they were theoretical performers, spectators, or alternating between the two. ${ }^{10}$ Whenever one's behaviors or gestures are the object of another's attention, he or she is seen, metaphorically speaking, as being "on stage" (performing). When one is engaged in the business of monitoring others, he or she is defined as audience or spectator. The nature of the audience's behavior is a consequence of members " "impressions" about the performance. The performer's subsequent behavior is in turn influenced by his or her reading of the audience. The character of much social action is regarded as a consequence of the adjustments interactants make to "the impressions" they formulate about each other.

We suggest that the character and direction of the victory crowds we observed can be best understood in terms of the interaction among the participants who either functioned as performers and spectators, or alternated between the two categories. We will first consider the performers, and then examine the "proximal spectators" and their relative influence. Since the police functioned as both spectators and performers, their behavior and influence are considered in relation to another audience, the bystanders or "distal spectators."

\section{Task Performers}

During the course of the celebrations a variety of activities were readily observable. Wright (1978), who similarly reported considerable behavioral heterogeneity during his first-hand examination of collective encounters, has suggested that these behaviors may be differentiated according to whether they are "task" or "crowd" activities. Crowd activities refer to redundant behaviors seemingly universal to all collective encounters, such as assemblage and milling. Task activities include those behaviors that are particular to and necessary for the attainment of a specific goal or resolution of a specific problem. From a dramaturgical standpoint, we would add that task activities constitute the primary objects of attention, and that those crowd participants engaging in such activities constitute the task performers.

Throughout the celebrations several task performers were clearly observable, such as the vehicular paraders, the "gropers," the dancers, and the police. There was even a group of religious fundamentalists that appeared one evening in an effort to promote their cause and recruit members. What distinguished the various task performers from the spectators is that rather than visually attending to the business of others, they engaged in activities specific to the tasks of celebrating, dancing, molesting women, or promoting Jesus. It was these performances that provided the spectators with something to view.

However, not all of the task performances were equally attended to by the spectators. Indeed it appeared as if all but the vehicular paraders, and later the police, were ignored. Consequently, it is useful to classify task activities according to the amount of attention they receive, and according to their salience to the character of the collective encounter. Those behaviors which are the major focus of attention and which give meaning to the occasion can be regarded as the main 
task activity. Those task performances subordinate to the main task activity constitute side or subordinate task activities. Put metaphorically, the major task activity is the main performance. It is on center stage. In contrast, the remaining task activities are side shows, subordinate and often parasitic to the main event. In the victory crowds the vehicular paraders functioned as the main task performers, at least until the fifth celebration when the police and their interaction with the paraders became the focus of attention.

Since the activities of the vehicular paraders were more in keeping with the spirit of the occasion, it is understandable why they, rather than the other task performances, were the focus of attention. But why did the paraders keep performing? Why was the performance confined to a specific spatial area? What defined "the stage?" What accounted not only for alteration in the behavior of the vehicular paraders, but also for the shift in orientation of the police? To answer these questions we must consider the spectators in detail.

\section{Proximal Spectators}

By proximal spectators we mean those physically co-present participants who function primarily as viewers. Whether voluntary or involuntary, animated or passive," their major activity consisted of watching the paraders celebrate.

Turner and Killian (1972:93-94) have noted that spectators constitute an important element of the crowd because they swell its ranks and thereby create the impression of solidarity. Our observations suggest that spectators function not only in this supportive manner, but they also define the character of the activity they observe. In some instances, spectators offered verbal or gestural support for a new line of activity exhibited by innovative paraders. In other instances spectators called for specific lines of action. Those "calls" included thrusting out an open palm in order "to get five" from the passing paraders, yelling for the performers to ignore the police, and urging the performers to get on with "the show." When the police began to curtail the noise, for example, groups of spectators would call for the paraders to honk their horns. Rather than only responding to the main task performance and accepting the activity as given, the more animated spectators attempted to influence the character of the celebration.

The presence of spectators also functioned to determine the level of animation and noise produced by the vehicular paraders. Whenever spectators were absent, the paraders were relatively quiet and motionless. The only apparent activity occurred when a car approached from the opposite direction and blew its horn. However, as the vehicles approached an area where spectators were present, the paraders would "go into play"; that is, they would begin to yell, blow their horns, hang out the window, and flash the "Hook-em-Horns" sign. This interactional pattern was so dominant that paraders would cease to celebrate once out of view of the spectators. Then, after turning their cars around and getting back on the Drag, the paraders would "turn on" or "come into play" once again.

The influence of the presence of spectators was demonstrated even more dramatically during the fourth celebration when many of the spectators moved north of the Drag, redefining the portion of Guadalupe between Twenty-Ninth and Thirty-First Street as the "new stage." The vehicular paraders driving into that 
area went into "play," performing as they had earlier when the Drag was defined as the arena for celebration.

These observations indicate that the audience more than the main task performers defined the stage or area in which the celebrations were conducted. It is thus reasonable to suggest that in this particular series of crowd episodes the audience, rather than being merely supportive or facilitative, was structurally essential. Simply put: no audience, no victory celebrations. ${ }^{2}$

\section{Social Control Agents and Distal Spectators}

Another group of actors which comprised part of the crowd and influenced the course and character of the celebrations were the police. We emphasized earlier that the character of the fourth celebration was strikingly different from those previous. Not only was there a discernible change in the behavior of the vehicular paraders, who had become more constrained, but there was a corresponding shift in the orientation of the police. Our observations suggest that the alteration in the activity of the main task performers was largely due to the change in the demeanor of the police.

Initially the police viewed the celebrations as good clean fun. They maintained a low profile, alternating between being supportive spectators and subordinate task performers. As one of the commanding officers commented after the first celebration:

This crowd was in a partying mood . . not a trouble-making mood. They were not intent on tearing up anything. Far be it from us to interfere with a good party.

In the midst of the third celebration another officer, who stood on the sidewalk watching the "party," similarly commented that "there's not much else we can do. They're just having fun." There were other lines of action that might have been pursued, but the police had adopted a policy of nonintervention. In the middle of the week prior to the fourth celebration a public information officer confessed that the police had been "rather lenient the last three weeks," adding that "we have not put some people in jail that we could have." However, shortly after the fourth celebration began it was clear that the police had redefined the crowd activity as something other than "fun." Twice as many officers were assigned to the Drag, and they were wearing riot helmets and high boots. They were also less congenial and more task oriented. Instead of standing on the sidelines and flashing the "Hook-em-Horns"' sign, they were now stopping the paraders. They directed people to remain in their cars and to refrain from blowing their car horns. They issued warnings and citations. Finally, and most significantly, by the end of the evening the police had arrested several celebrants.

In attempting to control the proceedings, the police had become a focus of attention for both the vehicular paraders and the proximal spectators. They were competing with the vehicular paraders for control of "center stage," while simultaneously neutralizing the influence of the animated spectators. What was previously an occasion condoned or tolerated by the police had been redefined as an 
occasion that needed to be controlled and diffused. What transpired between the third and fourth celebrations to account for the change?

The answer to this question requires consideration of another audience that Turner and Killian (1972:238-240) have termed a "bystander public." The concept denotes a diffuse collectivity that emerges when prolonged crowd behavior is perceived as a threat to personal routines and public order. According to Turner and Killian (1972:238), bystanders have no particular stake in the demonstration, celebration, or conflict that constitutes an object of attention. Rather, they are concerned with the "restoration of order and the elimination of danger and inconvenience," whether real or anticipated. Since our observations indicate that each celebration prompted the emergence of bystander spectators, and that their responses were not all unfavorable, we find it necessary to broaden the conceptualization. Accordingly, we define a bystander public or audience as a diffuse collectivity of distal spectators who indirectly monitor an instance of crowd behavior and respond to it, either favorably or unfavorably, by registering their respective views with the media, the press, and/or with community officials. ${ }^{13}$ Although not directly involved in the crowd attended to, distal spectators can effect its career and outcome by indirectly influencing one or more groups of participants.

Our research indicates that the emergence of distal spectators did indeed influence the behavior of the police in particular and the character of the celebrations in general. This observation is suggested by the data derived from a content analysis of all celebration-related articles, editorials, and letters-to-the-editors appearing in the Austin American Statesman and the University Daily Texan from the day after the first celebration to seven days following the last regularly scheduled game. ${ }^{14}$ As indicated in Figure 2, which summarizes the findings, it was not until the week following the third celebration that distal spectators began to clamor for the control and dissolution of the celebrations. Since the change in police demeanor and strategy occurred during the following (fourth) celebration, we argue that the shift was largely attributable to the emergence of distal spectators who viewed the celebrations negatively, publicly calling for the restoration of order.

Prior to the third celebration, distal spectators, including the press, responded favorably to the victory crowds. Following the first celebration, for example, the city newspaper referred to the celebration as "Happy Days;" and a letter to the editor encouraged celebrants to "Keep (their) Horns High." The following week such terms as "ecstasy" and "joy" were still being used to describe the celebrations. However, by the end of the week following the third celebration it was clear that either there had been a change in attitude among distal spectators or that a less congenial group of distal spectators had emerged. Whatever the case, not only had the celebrations become more of a community issue, as evidenced by the increase in the number of newspaper accounts devoted to them (see Figure 2), but the celebrations were now being described as "unruly," "childish," "drunken sprees," "expensive," and "public disturbances." In response to the negative public reaction, local officials urged the celebrants to "cool it." On the Thursday following the third celebration, the city mayor issued a press release in which she 
Figure 2. Number of Articles and Editorials Responding Favorably or Negatively to the Celebrations.

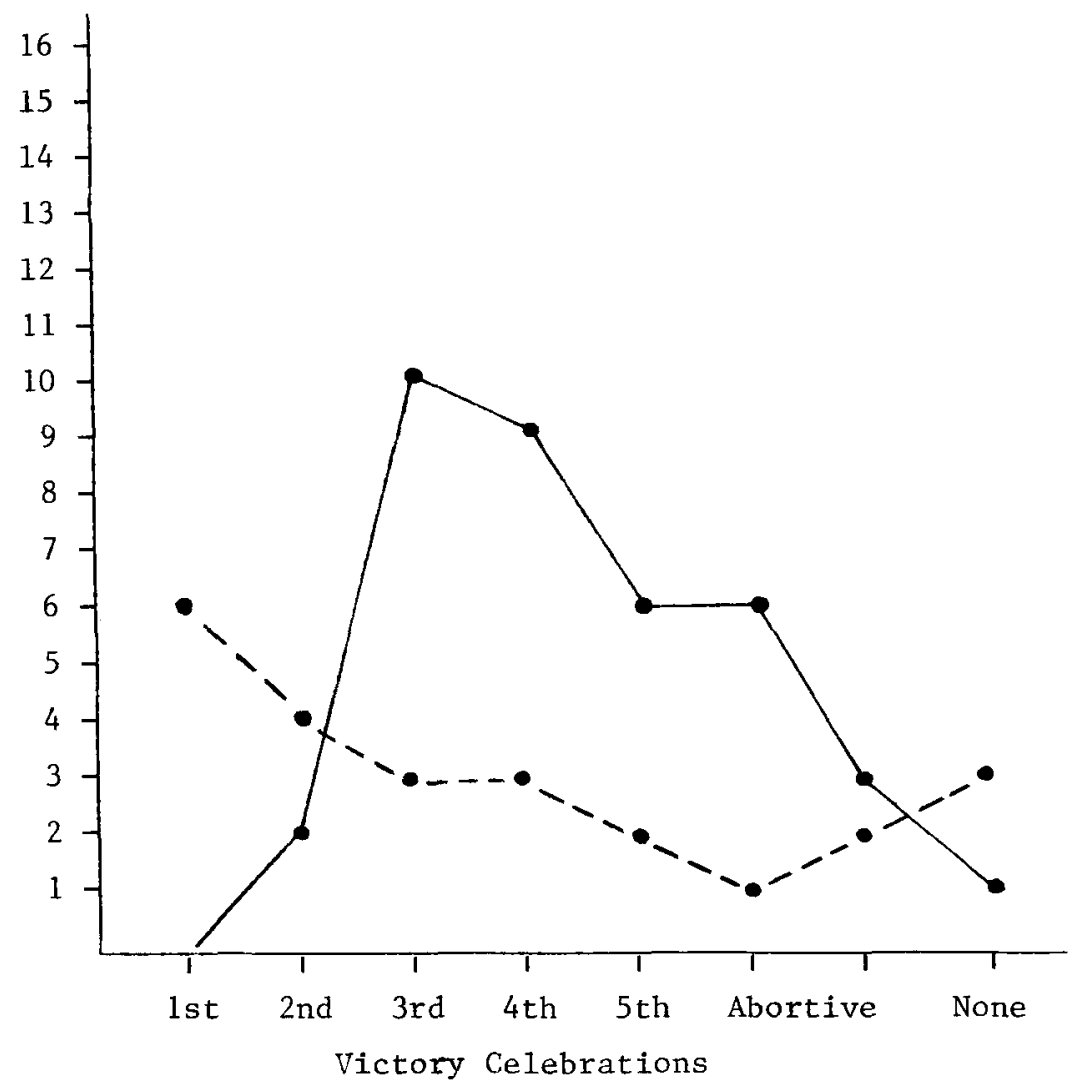

Key: - - - Neutral to Favorable - Neutral to Negative

called on the police to "clamp down" on the celebrants whose actions "would harm any citizen, damage property or abuse any individual's rights." In a letter appearing in the campus newspaper on the same day, a university official called on "students to exercise . . . maturity and good judgment," and warned that continued celebration would make "large numbers of students subject to traffic citations, arrests, and prosecution."

In light of the distal spectators redefinition of the celebrations as "disturbances," and their demand for celebrant restraint and police vigilance, the change in police behavior is understandable. Although this change altered the character of the fourth celebration, distal spectators continued to pressure public officials to control the "fanatics" and put an end to the "curse." The police thus maintained 
their "show-of-force" and "crack-down" strategy. As a result, the fifth celebration was the most subdued to date. In the weeks that followed, the police were the only group of actors to appear in significant presence. By the time the last regularly scheduled game was completed, it was clear that the police had become the main task performers. The Drag was once again a street rather than an arena for celebration. As one supportive distal spectator commented, "the spectacle wasn't loyal Texas fans waving their horns, but the 80 or so cops who lined the Drag."

In summary, our observations suggest that just as the activity of the vehicular paraders was influenced by the proximal spectators, including the police, so the police activity, and ultimately the character of the celebrations, was influenced by the emergence of distal spectators calling for the restoration of order.

\section{CONCLUSIONS AND IMPLICATIONS}

This paper has described and analyzed a series of victory celebrations that were observed as they evolved. Post hoc analysis revealed that existing theories of crowd behavior were either contradicted by our observations or did not adequately account for the heterogeneity of activity observed. Nor did they account for the interaction among the various categories of participants, or for the shifts in behavior of the participants and the resultant change in the character of the celebrations. Subsequent analysis indicated that the celebrations could best be understood from a dramaturgical standpoint. Dramaturgy views social action as the consequence of the adjustments interactants make to the impressions they formulate about each other in specific situations. Behavior is seen as situationallyconstructed action. As such it cannot be accounted for by reference to predispositions, whether they be demographic or cognitive. When applied to crowd behavior, dramaturgy shifts emphasis from concern with the backgrounds and dispositions of the participants to the emergent and ephemeral roles (Zurcher, 1979) they construct. Such an approach provides little insight into socio-historical conditions that give rise to crowd behavior. Nor does dramaturgy account for why some individuals rather than others participate in specific crowd episodes. But dramaturgy does focus attention on what has generally been regarded as a key defining characteristic of crowd behavior but which has seldom been the object of empirical investigation-crowd-specific interaction. Therein lies the analytic strength and utility of a dramaturgical approach to crowd behavior.

Several theoretical, conceptual, and research implications for understanding crowd behavior emerge from our observations and from our application of dramaturgy.

First, a dramaturgical approach to crowd behavior neither contradicts nor displaces the gaming or emergent norm perspectives. Instead, it complements them and provides a perspective into which both can be integrated. Since interaction, from a dramaturgical standpoint, is contingent upon the role-taking and rolemaking processes (Brissett and Edgley, 1975), a dramaturgical approach to crowds assumes what the gaming or rational calculus perspective emphasizesrationality on behalf of crowd participants.

A dramaturgical approach to crowd behavior also acknowledges the salience of 
emergent norms, but with two qualifications. First, there is seldom, if ever, one overarching norm that influences the behavior of all participants. Rather, there are different norms that are specific to different categories of actors. Second, a dramaturgical view suggests that emergent normative understandings are largely the function of verbal and non-verbal interactions and negotiation between main task performers and spectators.

Second, the observation that the character and direction of the celebrations were largely the result of interaction among several categories of performers and spectators suggests that spectators are structurally essential for the emergence of some, and perhaps all, forms of crowd behavior. Although several scholars have suggested that spectators contribute to the overall context of collective encounters, they are generally regarded as being a relatively passive and nonessential element in the crowd process (Turner and Killian, 1972; Wright, 1978). Certainly collective task performers could carry out their tasks independently of spectators (Wright, 1978:71). But would they? Our findings suggest that both proximal and distal spectators not only help to define the arena in which crowd behavior occurs, but that they also influence the pattern of activity they observe. We thus argue, from a dramaturgical standpoint, that the relationship between spectators and task performers is reciprocal and frequently interdependent. The extent to which this interdependence obtains is an empirical question. But until the relationship between performers and spectators is better understood for different types of crowd behavior, analyses which fail to examine the influence of spectators are likely to be one-sided and incomplete.

Third, our findings raise additional questions about "sequenced" approaches to crowd behavior. For example, it would have been impossible to describe the pattern and evolution of the victory celebrations according to Smelser's (1962) stages of collective behavior. ${ }^{15}$ The ad hoc nature of the interactions among different types of participants, and the shifting of those situational interactions. defies categorizing by a fixed and limited set of stages. Heirich's (1971) work on the "spiraling" nature of crowd behavior, though not specific enough about interactive phenomenon, seems more useful and consistent with our observation and analysis.

A fourth implication pertains to the relation between crowd behavior and everyday behavior. Crowds have generally been viewed as explicable only in terms of concepts specific to collective behavior itself. With the exception of a few scholars (Berk, 1974a; Brissett, 1968; Brown and Goldin, 1973; Couch, 1968, 1970; Johnson, 1974, 1977; McPhail and Miller, 1973; Turner and Killian, 1972; Weller and Quarantelli, 1973), discussions of crowd behavior have eschewed concepts relevant to everyday, institutional life. This tradition has emphasized the difference between collective and everyday behavior. Moreover, it has undermined integration of theories of social behavior.

In contrast, the dramaturgical approach applies to both crowd and everyday behavior. The interactive mechanisms that characterize social interaction in everyday life are assumed to be operative in crowd behavior. The differences are largely spatial and temporal in character. Everyday behavior is usually scheduled and acted in spatial areas or structures designed and traditionally used for such 
behaviors. Crowd behavior, on the other hand, is more likely to be unscheduled and staged in spatial areas and structures that were designed and are currently used for purposes other than crowds-that is, for so-called institutional or everyday behavior. ${ }^{16}$

Implicit within the foregoing distinction between everyday and crowd behavior is an expanded conception of crowd behavior. It is behavior that is not only guided by emergent norms (Turner, 1964a, 1964b; Turner and Killian, 1972) or characterized by emergent social relationships (Weller and Quarantelli, 1973). It is also characterized by the appropriation and use of a spatial area (street, park, mall) or physical structure (building) for purposes other than those for which it was intended at a particular time. It may well be that the collective appropriation of space for purposes other than intended constitutes, from a phenomenological standpoint, a key factor in defining crowd behavior as something special. It is the unanticipated appropriation that alerts us that something out-of-the-ordinary is occurring. Football fans charging onto the playing field with 30 seconds remaining in the game is thus viewed as an instance of crowd behavior; fans charging onto the field 30 seconds after the game is completed is seen as ordinary fan behvior. Viewed from a dramaturgical standpoint, crowd behavior may thus be regarded as a social production constructed during the course of interaction in a spatial area or structure that has been appropriated and redefined for purposes other than designed or intended at a particular point time. Crowd behavior, therefore, along with everyday behavior, is not only an interactional phenomenon, but has a spatial and temporal dimension as well. The relative weight of each of these components in the generation of crowds, and the manner in which the components interact in the processes of crowd behavior, are fertile areas for further research.

\section{NOTES}

1. There has, of course, been a proliferation of research on crowds since the early 1960s. However, aside from a few studies (Berk, 1974a; Fisher, 1972; Heirich, 1971; McPhail, 1969; Seidler et al., 1976; Wright, 1978), the data have typically been "gathered before or after the crowd behavior occurs" (Marx and Wood, 1975:372). Hence, most of the research reveals little about patterns of interaction within collective encounters.

2. In suggesting that most of these works share a common focus of attention, we do not imply that their respective images of crowds or crowd participants are similar. In fact, many of the works focusing on either dispositions or cognitive states differ considerably in terms of their respective views of crowd participants. Some of these differences will be discussed later in the paper.

3. Because of the nature of the crowd behavior we observed, our analysis and generalizations pertain primarily to the compact crowd, and not to diffuse crowd phenomena or collective behavior in general. For a discussion of the distinction between compact and diffuse crowds, see Turner and Killian (1972:111).

4. The "Hook-em-Horns" sign is formed by extending the index and little fingers while at the same time curling the thumb and remaining two fingers. The hand thus forms a representation of the head of a "Longhorn" steer, the athletic mascot of The University of Texas. The hand, formed into the "Hook-em-Horns" sign, is thrust upward, above the head, in an exuberant manner.

5. The University of Texas at Austin had over 40,000 students in attendance in 1977.

6. These findings are similar to those reported by Aveni (1977) following a study of individuals participating in a victory celebration in Columbus, Ohio in 1974. Aveni found that 74 percent of the 204 persons interviewed were with one or more friends. In contrast to the "anonymity" assumption, such 
findings indicate that crowds include not only isolated individuals, but also persons in groups or who are socially linked with each other.

7. We would argue that a crowd composed of several categories of actors is more common than the leader-follower type. This is, of course, an empirical question. But our recollections of the student protests and urban disorders of the 1960s suggest that the leader-follower type of crowd is probably an empirical rarity that might therefore be best conceptualized as an ideal type of crowd.

8. It would also seem reasonable to argue that the risky-shift thesis may be more directly applicable to those situations involving considerable risk, a condition which did not appear to be the case with the celebrations. But just how "risky" a situation or particular line of action is or appears from the vantage point of the participants is difficult to ascertain. Certainly the degree of risk cannot be assumed a priori. Nor can the absence of risk or minimal risk be inferred from action in a particular direction. To do so strikes us as tautological.

9. The best known dramaturgical analysis within sociology is provided by Goffman (1959). For a fuller discussion of dramaturgy as a mode of analysis, see Brissett and Edgley (1975), Burke (1962. 1965), and Messinger, et al. (1975). A dramaturgical approach to crowd behavior is implicit in the work of Brissett (1968) and Brown and Goldin (1973).

10. We are not inferring anything about the actor's consciousness. That is, we are not assuming or arguing that interactants are consciously or intentionally engaged in impression management. Instead, the theatrical model is invoked "as a device, a tool ... to focus attention on the consequences of those perceptions or "impressions" for subsequent action (Messinger, et al., 1975:37).

11. The distinction between animated and passive spectators has already been noted. Voluntary spectators refer to those individuals who have chosen to observe the main task performers. Involuntary spectators refer to those individuals who have no interest in the proceedings, but who find themselves functioning as spectators because they live or work in the immediate area in which the crowd episode is occurring, or because they are passing through it. Their presence at the scene of the collective encounter is therefore largely coincidental. For further discussion of different types of spectators, see Wright (1978).

12. The importance of the audience in relation to crowd activity was indicated again two months later when The University of Texas unexpectedly upset the nationally third ranked University of Arkansas in basketball. All the elements for a post-game celebration were seemingly present: an unanticipated event; a lack of conflicting student commitments (it was Saturday night); assembling instructions were voiced (several fans yelled "to the Drag" and "Let "s go to the Drag"); several "horn honking" autos were on the Drag. But there was no crowd celebration. A main ingredient was missing. There were no spectators to define the stage and to provide encouragement and support. With the exception of a few "horn honking" autos, the post-game traffic moved quietly and quickly along the Drag, stopping only for traftic signals. No police were present.

13. It may appear that we have merely rediscovered public opinion. It is important to emphasize that we do not see distal spectators or public opinion as being conceptually interchangeable or empirically identical. What is frequently construed as public opinion typically represents the solicited responses of a sample of individuals. In contrast. the responses of distal spectators are unsolicited. Distal spectators make a concerted effort to air their views in hopes of stimulating or retarding the crowd behavior in question. Moreover, the opinion of distal spectators may not be in accord with so-called public opinion.

14. Sixty-one celebration-related accounts appeared in the 2 newspapers during the 8 week period in question. The newspaper accounts were categorized according to whether they were (1) negative in tone or control-oriented; or (2) favorable towards or supportive of the celebrations. Thirty-five of the newspaper accounts were classified as control-oriented or negative in tone; twenty-six fell into the supportive or favorable category. The $6 \mathrm{I}$ newspaper accounts were coded independently by two of the authors. There were no major coding disagreements or discrepancies.

15. For other critiques of Smelser's value-added approach to collective behavior, see Brown and Goldin, 1973; Currie and Skolnick, 1970; Milgram and Toch, 1969; Oberschall. 1973; Quarantelli and Hundley, 1969.

16. It is important again to emphasize that we are referring to collectivities that can best be described as compact crowds. Diffuse crowds, such as fads, fashion, and forms of mass hysteria, are seldom limited to or played-out in spatial areas or physical structures intended for everyday behavior. 


\section{REFERENCES}

Allport, Floyd $\mathrm{H}$.

1924 Social Psychology. Boston: Houghton.

Aveni, Adrian F.

1977 "The not-so-lonely crowd: friendship groups in collective behavior." Sociometry 40: 96-99.

Berk, Richard A.

1974a "A gaming approach to crowd behavior." American Sociological Review 39: 355-73.

1974b "Collective behavior." Dubuque, Iowa: Wm. C. Brown.

Blumer, Herbert

1951 "Collective behavior.” Pp. 167-222 in A.M. Lee (ed.), Principles of Sociology. New York: Barnes and Noble.

1957 "Collctive behavior." Pp. 127-58 in J.B. Gittler (ed.), Review of Sociology Analysis of a Decade. New York: Wiley.

Brissett, Dennis

1968 "Collective behavior: the sense of a rubric." American Journal of Sociology 74: 70-78.

Brissett, Dennis and Charles Edgley (eds.)

1975 Life as Theater: A Dramaturgical Sourcebook. Chicago: Aldine Publishing Company.

Brown, Michael and Amy Goldin

1973 Collective Behavior. Pacific Palisades, CA.: Goodyear.

Brown, Roger

1965 Social Psychology. New York: Free Press.

Burke, Kenneth

1962 A Grammar of Motives and A Rhetoric of Motives. New York: The World Publishing Co.

1965 Permanence and Change. Chicago: Bobbs-Merrill.

Couch. Carl J.

1968 "Collective behavior: an examination of some stereotypes." Social Problems 15: 310-22.

1970 "Dimensions of association in collective behavior episodes." Sociometry 33: 475-71.

Currie, Elliot and Jerome Skolnick

1970 "A critical note on conceptions of collective behavior." Annals of the American Academy of Political and Social Sciences 391: $34-45$.

Feuer, Lewis L.

1969 The Conflict of Generations. New York: Basic Books.

Fisher, Charles $\mathrm{S}$.

1972 "Observing a crowd." Pp. 187-221 in J.D. Douglas (ed.), Research on Deviance. New York: Random House.

Freud, Sigmund

1922 Group Psychology and the Analysis of the Ego. London: The Hogarth Press.

Goffman. Erving

1959 The Presentation of Self in Everyday Life. Garden City, New York: Doubleday.

Gurr, Ted R.

1970 Why Men Rebel. Princeton, N.J.: Princeton University Press.

Heirich, Max

1971 The Spiral of Conflict: Berkeley, 1964. New York: Columbia University Press.

Johnson. Norris R.

1974 "Collective behavior as group induced shift." Sociological Inquiry 44: 105-10.

Johnson, Norris R. and William E. Feinberg

1977 "A computer simulation of the emergence of consensus in crowds." American Sociological Review 42: 505-21.

Johnson, Norris R., James G. Stemler and Deborah Hunter 1977 "Crowd behavior as risky-shift: a laboratory experiment." Sociometry 40: 183-87.

Klapp, Orrin E.

1969 Collective Search for Identity. New York: Holt, Rinehart and Winston.

1972 Currents of Unrest: An Introduction to Collective Behavior. New York: Holt. Rinehart and Winston. 
Lang, Kurt and Gladys Lang

1968 "Collective behavior." Pp. 556-65 in D.L. Sills (ed.), International Encyclopedia of the Social Sciences. New York: MacMillan and Free Press.

LeBon, Gustave

1903 The Crowd. London: Unwin.

Marx, Gary T.

1970 "Issueless riots." Annals of the American Academy of Political and Social Sciences 391: $21-33$

Marx, Gary T. and James L. Wood

1975 "Strands of theory and research in collective behavior. "Pp. 363-428 in A. Inkeles, J. Coleman and N. Smelser (eds.). Annual Review of Sociology, Vol. 1. Palo Alto, CA.: Annual Reviews, Inc.

McPhail, Clark

1969 "Student walkout: a fortuitous examination of elementary collective behavior." Social Problems 16: $441-455$.

McPhail, Clark and David Miller

1973 "The assembling process: a theoretical and empirical examination." American Sociological Review 38: 721-35.

Messinger, Sheldon E., Harold Sampson and Robert D. Towne

1975 "Life as theater: some notes on the dramaturgic approach to social reality." Pp. 32-42 in D. Brissett and C. Edgley (eds.), Life as Theater. Chicago: Aldine.

Milgram, Stanley and Hans Toch

1969 "Collective behavior: crowds and social movements." Pp. 507-610 in G. Lindzey and E. Aronson (eds.), The Handbook of Social Psychology, Vol. 4. Reading, Mass.: AddisonWesley.

Miller, Neal E. and John Dollard

1941 Social Learning and Imitation. New Haven: Yale University Press.

Oberschall, Anthony

1973 Social Conflict and Social Movements. Englewood Cliffs, N.J.: Prentice-Hall.

Perry, Joseph B. and M.D. Pugh

1978 Collective Behavior: Response to Social Stress. New York: West Publishing Co.

Quarantelli, Enrico L. and James R. Hundley, Jr.

1960 "A test of some propositions about crowd formation and behavior." Pp. 538-54 in R.R. Evans (ed.), Readings in Collective Behavior. Chicago: Rand McNally.

Seidler, John. Katharine Meyer and Lois MacGillivray

1976 "Collecting data on crowds and rallies: a new method of stationary sampling." Social Forces 55: $507-519$.

Smelser, Neil $\mathbf{J}$.

1962 Theory of Collective Behavior. New York: Free Press.

1970 "Two critics in search of a bias: a response to Currie and Skolnick." Annals of the American Academy of Political and Social Sciences 391: 46-55.

Toch, Hans

1965 The Social Psychology of Social Movements. Indianapolis: Bobbs-Merrill.

Turner, Ralph H.

1964a "Collective behavior." Pp. 382-455 in R.E.L. Faris (ed.). Handbook of Modern Sociology. Chicago: Rand McNally.

$1964 b$ "New theoretical frameworks." Sociological Quarterly 5: 122-32.

Turner, Ralph H. and Lewis M. Killian

1957 Collective Behavior. Englewood Cliffs, N.J.: Prentice-Hall.

1972 Collective Behavior, 2nd Ed. Englewood Cliffs, N.J.: Prentice-Hall.

Turner, Ralph H. and Samuel J. Surace

1956 "Zoot-suiters and mexican symbols in crowd behavior." American Journal of Sociology 62: $14-20$.

Weller, Jack M. and Enrico L. Quarantelli

1973 "Neglected characteristics of collective behavior." American Journal of Sociology 79: 66585. 
Wright, Sam

1978 Crowds and Riots: A Study in Social Organization. Beverly Hills, CA.: Sage Publications. Zurcher. Louis

1979 "Role selection: the influence of internalized vocabularies of motive." Symbolic Interaction 2: $16-30$. 